\title{
The Impact of Fake News and the Emerging Post-Truth Political Era on Nigerian Polity: A Review of Literature
}

\author{
Umaru A. Pate ${ }^{1}$, Danjuma Gambo ${ }^{2}$, Adamkolo Mohammed Ibrahim² \\ ${ }^{1}$ Department of Mass Communication, Bayero University, Kano, Kano State, Nigeria \\ ${ }^{2}$ Department of Mass Communication, University of Maiduguri, Borno State, Nigeria \\ Correspondence: Adamkolo Mohammed Ibrahim, Department of Mass Communication, University of Maiduguri, PMB \\ 1069, Maiduguri, Borno State, Nigeria. E-mail: adamkolo@unimaid.edu.ng
}

Received: April 29, 2019

doi:10.11114/smc.v7i1.4238
Accepted: May 24, $2019 \quad$ Online Published: May 27, 2019

URL: https://doi.org/10.11114/smc.v7i1.4238

\begin{abstract}
Since the rising to notoriety of the present 'genre' of malicious content peddled as 'fake news' (mostly over social media) in 2016 during the United States' presidential election, barely three years until Nigeria's 2019 general elections, fake news has made dangerously damaging impacts on the Nigerian society socially, politically and economically. Notably, the escalating herder-farmer communal clashes in the northern parts of the country, ethno-religious crises in Taraba, Plateau and Benue states and the furiously burning fire of the thug-of-war between the ruling party (All Progressives Congress, APC) and the opposition, particularly the main opposition party (People's Democratic Party, PDP) have all been attributed to fake news, untruth and political propaganda. This paper aims to provide further understanding about the evolving issues regarding fake news and its demonic impact on the Nigerian polity. To make that contribution toward building the literature, extant literature and verifiable online news content on fake news and its attributes were critically reviewed. This paper concludes that fake news and its associated notion of post-truth may continue to pose threat to the Nigerian polity unless strong measures are taken. For the effects of fake news and post-truth phenomena to be suppressed substantially, a tripartite participation involving these key stakeholders - the government, legislators and the public should be modelled and implemented to the letter.
\end{abstract}

Keywords: democracy in Nigeria, disinformation, fake news, fake news in Nigeria, Nigerian politics, post-truth political era in Nigeria

\section{Introduction}

\subsection{An Overview of Fake News Issues in Nigeria}

Nigeria is a country in tension characterised by security threats in different parts of the country. These threats are manifested in forms of multiple conflicts, systemic and widespread corruption, debilitating poverty, weak institutions, threats of secession as well as perceived marginalisation, anger, hatred and economic challenges in a time when preference for untrue information is rising - i.e., post-truth era (Harsin, 2018; Pate, 2018 September 7). These issues are offensively, progressively and relentlessly destroying relationships, heightening animosities across communities and threatening democratic survival in the country (Pate, 2018 September 7). Arguably, all of that are facilitated by the revolution in information and communication technologies (ICT) that have democratised and simplified access and dissemination of information across space and time (Ibrahim \& Adamu, 2016; Pate \& Idris, 2017).

Cited in Premium Times Nigeria, Professor Umaru Pate, the Dean, School of Postgraduate Studies, Bayero University, Kano (BUK) explained that like many other countries, Nigeria, too, is battling with the rise in populism politics, youth radicalisation, extremism, terrorism, drug and human trafficking, ethnic nationalism, hate and dangerous speech, fake news and the rewriting of the country's history, among others. Indeed, these are critical times for the media and the country. The political climate in the country has changed rapidly in recent years, signaling innovative developments and strange challenges in the country's democratic system. By and large, the current political culture in the country is inextricably linked to the growing development of information and communication technologies (ICT) (Audu, 2018 September 9; Pate, 2018 September 7). Cited in Vanguard, Professor Danjuma Gambo, the Dean, Faculty of Social Sciences, University of Maiduguri who is also the Director, Public Relations of the university agrees with Professor Pate that fake news can mislead the public and cause tension in an already tense political climate with communal and 
reprisal attacks here and there in addition to the Boko Haram conflict. He stressed that if the media would cultivate the culture of verifying information and fact checking (if necessary) before going to press, the spread of fake news can be contained (Marama, 2017 August 10).

This has severally affected the delivery and form of political communication and the communication of political ideas in our democratic system, as well as shifted and undermined the accountability for those messages. For instance, what was labelled 'yellow journalism' and 'character assassination/slander' have metamorphosed into what is today known as 'fake news' and 'fraudulent news'; these are terms that sound 'big' and portend devastating effects in the society. These terms are fuelled and spread by the power of modern technology (Wasserman \& Madrid-Morales, 2018; Agbese, 2017 December 31). In the words of Egan (2018, December 11, online), "online, lies and truth look the same. This has been a boon for professional liars, (who) use these platforms to market falsehood; as vehicles for personal fame, or, as a way to spread propaganda". These have raised concerns that Nigerians are constantly and increasingly accessing inaccurate and/or misleading content without verification (gatekeeping) or verifiable attribution (Agbese, 2017; Hankey, Marrison, \& Naik, 2018).

Fundamentally, the breed of 'yellow journalism', 'fabricated or manipulated stories' 'fraudulent content' and 'character assassination' and 'fake news' are largely new technology-dependent (e.g., social media platforms and the internet) rather than traditional technologies such as radio, TV, newspaper or magazine (Okoro, Abara, Umagba, Ajonye, \& Isa, 2018; Wasserman \& Madrid-Morales, 2018 November 21). Thus, while we grapple with what modern technology has enabled us to do, "we also face a new wave of change, which we have only started to understand the ramifications of" (Hankey et al., 2018, p. 6). For example, the concerns around recent, or newer technologies such as 'artificial intelligence' and 'machine learning' show that any regulatory response to stem fake news peddled via new technologies, whether by state actors or technology developers, need to be as "dynamic as the technological mischief it seeks to contain" (Hankey et al., 2018, p. 6).

The critical question is: how can politics aid regulations to spur the development and sustainability of our democratic system while preserving its legitimacy to embrace internet-based and social media platforms in the context of promoting the integrity and values of the democratic process in a multicultural Nigeria? This paper focuses on the trend of fake news and the emerging post-truth political era and their potential impacts on the Nigerian polity. Recommendations for mitigating the negative effects of fake news and post-truth political circumstances in the society are offered at the concluding sections.

\section{Literature Review}

\subsection{Understanding Fake News}

The term 'fake news' is "false, often sensational information disseminated under the guise of news reporting" (Collins Dictionary, 2017, online). The term is gaining global attention over the years that it was named the Collins Dictionary Word of the Year in 2017 due to its increased usage by 365\% in the Collins Corpus (Towers-Clark, 2018, October 4). According to the Ethical Journalism Network (EJN), fake news is information deliberately fabricated and published with the intention to deceive and mislead others into believing falsehood or doubtful messages (EJN, 2017). The British Broadcasting Corporation (BBC) defines fake news as "completely false information, photos or videos purposefully created and spread to confuse or disinform; information, photos or videos manipulated to deceive, or old photographs shared as new; satire or parody which means no harm but can fool people" (BBC News, 2019 June 29, online). Globally, the issue of fake news has assumed increased concern because of its impact in the 2016 US Presidential elections campaigns and the Brexit referendum.

Furthermore, one of Nigeria's independent verification and fact-checking platforms, Dubawa, which is supported by the Premium Times Centre for Investigative Journalism (PTCIJ) defines fake news or false information as fraudulent, inaccurate or false verbal or visual messages disseminated for public attention through the conventional or social media, hugely to mislead, disinform or misdirect. It is a fluid subject that is differently perceived, interpreted and understood by individuals depending on many factors. Fake news is often embellished, sensationalised and made alarmingly attractive. Sometimes, it can be difficult to detect fraudulent news especially when such stories contain authoritative lies except through critical examination of the words mostly designed to capture and retain the attention of receivers in uncommon ways. Fake news is subtly and sophisticatedly presented to hide its falsity with unverifiable sources or claims. Fake news violates contextual and multicultural realities through mischief and ignorance presented as valid information (Dubawa, 2019, Ting \& Song, 2017). Furthermore, Steinmetz (2018 September 6, online) notes that fake news debases the truth and causes "confusion of fantasy and reality" in the minds of the audience.

As noted by Siapera (2018), there are three significant factors that characterise the current brand of fake news. First, the ease by which people can create contents; second, the distribution patterns across new and social media, and third, the political economy of the online domain which enables and incentivises the creation of these forms of news. She further 
noted that anyone with internet access can effectively produce and distribute contents of any kind of quality and that "people can avail of the various functionalities of computer software such as photoshop and create highly believable contents.... Fake news can travel very far on the internet" (Siapera, 2018, p.57).

The 'profile' of fake news was facilitated by the advent of the internet; the rise of populism politics in different parts of the world like the 2016 US presidential election (Davies, 2017; Persily, 2017); the rise of tyrannical leaders, and; the Brexit referendum (McGonagle, 2017). Fake news is a complex phenomenon that can be defined based on three parameters as suggested by Wardle (2017): the type of content created and shared; the intentions of those behind this, and; the forms of dissemination. Wardle (2017) further identified seven different categories of fake news in the following order: satire/parody, misleading content, impostor content, fabricated content, false connection, false context and manipulated content. In another way, one can collapse the seven categories into two broad forms of fake news, namely (i) high-profile fake news (see McGonagle, 2017; Tower-Clark, 2018) and (ii) low-profile fake news (see McGonagle, 2017; Mendel, 2015). High-profile fake news refers to misleading information and other contents that emanate from prominent sources while low-profile fake news is simply the opposite of high-profile fake news, that is, disinformation that emerges from subtle, inconspicuous, or ordinary sources. In addition, four specific sources of fake news have been variously identified: (i) state/government fake news (ii) organisational/institutional fake news (iii) group-based fake news and (iv) individual fake news (BBC News, 2018 November 12; Simon, 2017; Mendel, 2015).

Fake news is a real challenge in Nigeria especially given the country's fragile social setting, loose democratic culture, poverty, illiteracy, depressing human conditions, inflation, weak economy, intolerance and high tendencies for disunity among the peoples of the country (Ogola, 2017 February 27). As Nigeria rises to curb the negative impact of fake news on its democratic process, Pate (2018 September 7) offers some recommended to help individuals and newsrooms to instantly identify and avoid being victims of fake news:

1) Check sources: individuals are encouraged to fall back on most trusted news brands they could rely on for their news.

2) Fact-check from multiple sources

3) Use verification tools

4) Check metadata

5) Think before broadcasting/publishing

6) Media literacy: increase the standard of education and media literacy particularly for young people to be highly critical on what to trust on conventional and social media platforms

7) Use fact checking sites

8) Individuals and newsrooms should institute the culture of fact-checking for stories and claims

A good introduction answers these questions in just a few pages and, by summarising the relevant arguments and the past evidence, gives the reader a firm sense of What was done and why (Beck \& Sales, 2001).

2.2 Why Fake News Spreads Fast?

Fake news is not new. It is as old as one can remember. However, its intensification is more in recent times because of the wide usage of the internet and cheap access to social media platforms, competitive politics and deepening poverty and ethno-religious fight for supremacy. Many more reasons can be adduced for the fast spread of fake news in the country. Some of the reasons have been outlined by Pate (2018 September 7) as follows:

1) General distrust of elites, leaders and politicians by majority of Nigerians. Nigerian elites and politicians enjoy low credibility rating among the population because of their record of failures, lies and unworthy conduct in several respects. Because of that, many Nigerians tend to believe whatever negative information dished out by opponents.

2) Absence or most often late arrival of official information on issues. This creates vacuum conveniently filled in by rumors and disinformation

3) Availability of cheap data services is facilitating explosive use of social media platforms (Facebook, WhatsApp, Twitter, YouTube) to spread of rumors, propaganda and fake information

4) Sensationalised fake news is disseminated for economic reasons, especially on social media, where efforts are often made to attract people to pages and timelines of bloggers and senders for clicks

5) Desperate politicians, ethnic and religious jingoists, foreign interests and mischief makers generate fake news for influence or to persuade the audience

6) Low capacity of the media to be able to gather, process and verify immediate and distant information in real time exacerbates fake news through the internet or social media platforms where majority lack gatekeeping processes. 
7) Government tight control as well as excessive commercialisation in the broadcast media exclude alternative ideas and the opposition thereby forcing them to response even if mischievously by spreading fake news on the social media that lack gatekeepers.

8) Authoritative lies are very common from government sources at all levels. Such lies are reported as news with little effort to investigate their veracity by the media

\subsection{Fake News and the Debates Over the Emerging Concept of 'Post-Truth Political Era'}

One key reason that makes fake news spreads fast nowadays, especially during political election times in developing countries such as Nigeria is, arguably, what Professor Pate calls "executive intimidating" while describing the relationships between journalists and politicians during a Mass Communication undergraduate class in 2004 at University of Maiduguri (Personal communication: 2004). Fake news thrives in Nigeria because nowadays objective facts are fast becoming as illusionary as a mirage to many Nigerians, especially citizens of social media. Stories and news appealing to the emotion and personal beliefs appear to be more believable and capable of shaping public opinion, a phenomenon that obviously seems to erode the credibility of gate-kept news and reports and verified content. This situation perfectly matches what is lately referred to as the 'post-truth' time (Harsin, 2018). Unsurprisingly, though, lying is often attributed to politicians; many of them do not regard telling a lie as bad behaviour, an argument Colin Wight, a Professor of International Relations at the University of Sydney agrees with, saying, "lying is not an aberration in politics". However, Professor Wight argues that "there is nothing new about politicians and the powerful telling lies, spinning, producing propaganda, [or] dissembling", a behaviour that is in tandem with Machiavellianism, that "all leaders might, at some point, need to tell lie."

Historically, this can be traced back to Plato's coinage of the term "noble lie", which refers to false information deliberately spread by a crème de la crème of the society, especially political elites to preserve social accord or promote an agenda (The Conversation, 2017 November 17, online). The English Oxford Dictionary (2019) defines post-truth as "circumstances in which objective facts are less influential in shaping public opinion than appeals to emotion and personal belief". As Professor Pate noted, looking at the strong affinity between fake news peddling and social media vis-à-vis the skyrocketing levels of social media use among Nigerians (Itedge News, 2018 September 10), in no time could the post-modernist Machiavellianism, noble lie, or untruth permeate the Nigerian polity and cause unimagined topsy turvy, a phenomenon the Nigerian Information and Culture Minister, Lai Mohammed describes as "the greatest threat to democracy and security" (Abdullahi, 2017 March 13, online). Hence, the need for urgent action to tackle the menace.

\subsection{The Possible Effects of Fake News in Nigeria}

The term 'fake news' is not new in the country. Simply, the attachment of the negative word 'fake' to the word 'news' heightens the degree of the perceived effect of the term. News, simply put, is an account of what happened. Because of the value attached to it, news is envisaged to be the truth. However, in the era of post-truth and for a Nigeria that has lived in non-truth for years even "the two fundamentally contradictory terms can occupy the same textual space" (Abdullahi, 2017 March 13, online). Recently, the BBC interviewed a group of Nigerian experts on their opinion about the greatest challenges of the $21^{\text {st }}$ Century. Many of them indicated that failure of credible information sources is one of the serious problems facing Nigerians, indeed, mankind.

In a related development, Professor Umaru Pate has criticised the Nigerian media, particularly broadcast media for allotting greater percentages of their news, reports and programmes to political matters, phenomena he was quoted by Itedge News (2018 September 10, online) to have said, "feast on hatred and incitements.... Everything political is news but burning issues poverty and violent conflicts do not seem to worry us. This is bad." The scholar went further to blame the rising levels of fake news in the country on the "absence of patriotism, ethnic and religious bigotries, political affiliations and foreign interests"

The Zonal Director of Nigerian Broadcasting Commission (NBC) in charge of the North-Central zone of Nigeria, Dr. Igomu Onoja cited in Itedge News argued that, "it [is] part of media ethics to ensure balance reporting and give all parties equal hearing" and desist from journalism capable of spreading fake news that could undermine the Nigerian democratic process. Dr. Onoja cites an example of fake news broadcast over a media outlet in Jos, Plateau State (north central of Nigeria) saying, "we have radio stations in Jos clapping for people that say that the Plateau governor is mentally deranged" (Itedge News, 2018 September 10, online).

As a matter of 'post-truth' fact, truth has nowadays shifted to becoming relative; facts now have alternatives, and news is weaponised, a phenomenon Abdullahi (2017 March 13, online) quoted Nigeria's Information and Culture, Minister, Lai Mohammed describing it as "the greatest threat to democracy and security as it played a role in the civil war in the country and that Nigeria could not afford to fall victim to the same circumstances that led to the war". Furthermore, 
realising the dangers of fake news, the Federal Government of Nigeria launched a national campaign against fake news on July 12, 2018 to enlighten Nigerians and counter its prevalence. Indeed, fake news is summarily unethical, dangerous, provocative, and subversive to peace and societal serenity especially in a multicultural setting like Nigeria as it heightens tension and build fear and mistrust among people. Fake news could "threaten and destroy" the country as the Minister of Information cautioned (Abdullahi, 2017 March 13, online).

Pate and Idris (2017, p.161) and Abdullahi (2017 March 13, online) cited Section 22 of the 1999 Constitution of Nigeria, which provides that, "The press, radio, television and other agencies of the mass media shall at all times be free to uphold the fundamental objectives contained in this chapter and uphold the responsibility and accountability of the government to the people". According to Abdullahi (2017 March 13, online), Section 39 of the 1999 Constitution states that: (i) every person shall be entitled to freedom of expression, including freedom to hold opinions and receive and impart ideas and information without interference; and (ii) without prejudice to the generality of Sub-section (1) of this Section, every person shall be entitled to own, establish and operate a medium for the dissemination of information, ideas and opinions.

The constitution was framed to promote, promote and uplift the process of democratisation. The constitution has clearly recognised freedom of expression and freedom of the press as fundamental elements in our democracy. Democracy thrives when people have free access to genuine and correct information about issues and matters that affect them to make informed decisions and choices (Oro, 2011; Epstein, 2011). Therefore, the escalating effects of fake news and 'alternative facts' are direct assaults on fundamental principles and practice of democracy. This is because while Section 39 of the Constitution provides for freedom to hold and impart opinions, ideas and information without interference, "interference is exactly what fake news does" Abdullahi (2017, March 13, online) notes. In fact, by battling for space and vying for acceptability with authentic information and news, fake news deprives people of the very constitutional right to hold opinions and receive and impart ideas and information (Abdullahi, 2017 March 13; Oro, 2011; Pate, 2018 September 7).

Side by side with authentic information, the creation of alternative facts often makes it difficult for people to distinguish truth from untruth. When people get confused as to what is the truth, or genuine information, they cannot create shared meanings in conversations, let alone hold their political representatives accountable for their stewardships. The Information and Democracy Commission (IDC, 2018 November) notes that: "Political control of the media, subjugation of news and information to private interests, the growing influence of corporate actors who escape democratic control, online mass disinformation, violence against reporters and editors, and the undermining of quality journalism, threaten the exercise of the right to knowledge" (p. 3).

1) Selective reporting and promotion of prejudices about groups and individuals based on stereotypes, incomplete facts, mischief and ignorance

2) Spreading of manipulative or fabricated stories and pictures regarding the complexities of our composition; often, matters are ethnicised, religionised, regionalised or politicised to the detriment of the collective good

3) Presentation of poorly researched information due to low capacities of media professionals thereby manifesting in shallow reporting and fake news

4) Common tendency of reporting inter-group conflicts out of their fundamental sociological, economic, political and other contexts, often resulting in fakery

5) The promotion of statements of politicians, ethnic champions, religious zealots and other interested parties without being critical or fact checking information about specific contentious issues

6) Generalised statements not supported by facts and figures on very sensitive national integrative issues

7) Official lies from governments and officials through established sources

Pate (2018 September 7) has highlighted the manner of dissemination of fake news in Nigeria. Some of these are through:

\subsection{Consequences of Fake News}

Pate (2018 September 7) has outlined some critical repercussions of fake news in the society as follows: (a) fake news can undermine the unity and peace of the country with explosive consequences; (b) by its nature, democracy looks adversarial, but fake news makes it worse; (c) fake news can exacerbate distrust, division and violence in the already divided diverse polity; (d) fake news can undermine confidence and certainty of the citizens in the media; and (e) fake news can promote anti-democratic tendencies that can subvert confidence in the system, undermine. 


\section{Conclusion and Recommendations}

\subsection{Conclusion}

The possible solutions to the menace of disinformation, or fake news and its consequences must be studied from a multifaceted perspective. As we struggle with the intricate politics of multiple identities of ethnicity, religion and regionalism, the undermining impacts of fake news in this era of post-truth make this challenge more complicated. As people continuously develop, share and promote contents that emphasise those fault lines, it would be nearly impossible to form a sense of national cohesion for our country. Without this, it would be unfeasible to develop a consensus around those fundamental issues that would spur our progress as a nation. The danger contained in disinformation is not the 'untrue' information itself; rather, it is what people do with the disinformation that gets to them. Historically, all conflicts started with words - what people say to themselves and what they say to others (Abdullahi, 2017 March 13; Agbese, 2017; Aminu, 2018; Ansip, 2017; Kazeem, 2018; Pate \& Idris, 2017). In our respective spheres of influence as citizens, we can make resolution not to fabricate, encourage or share any content that is fake or fraudulent. This may not solve all the problems 'post-truthfully' but could when people individually and collectively join to be part of the solution rather than the problem. Post-truth may have been lurking over our society, but it can be suppressed with strong legislations, policies and public participation. The government formulates policies based on legislative underpinning, which should create room for public participation in the anti-fake news, or anti-post-truth-effect campaign to disinfect the Nigerian polity of the effect of these lurking anti-social and anti-political orderliness.

\subsection{Recommendations on How to Identify Fake News and Mitigate its Menace in the Society}

Some of the best recommendations that this paper offers include those outlined by Pate (2018 September 7) as follows.

- Funding: the reality of fake news demands an appreciation of the architectural and technological models of digital messaging and how these models have reconstituted the meaning of social relations.

- Ethics: digitisation brought volume and velocity but failed to present veracity. Therefore, to resolve the enigma of fake news structurally, we need to inject the imperative of veracity to the messaging mechanism.

- Partnership: encourage partnership and networking between credible media organisations in and out of the country.

- Credibility: encourage media owners to support their media organisations for credibility and acceptability over the social media through the practice of quality journalism; this will reduce the attention accorded to fake information.

- Media skills: there is the need for increased and continuous training for conventional and social media journalists on issues of fake news.

- Regulation: regulatory bodies like National Broadcasting Commission (NBC) and Nigerian Press Council (NPC) deserve additional support and autonomy for unhindered regulation

- Collaboration: there is the need for increased involvement of professional bodies like the Nigeria Union of Journalists (NUJ) and the Radio, Television and Theatre Arts Workers' Union RATTAWU in calling members to order.

- Media literacy: there is the need for increased media literacy for the public, particularly young people to be critical in accessing and responding to media messages.

- Media Professionalism: the media should report accurately, responsibly and professionally in line with the media code of conduct in order to foster civil discourse.

- Gatekeeping and Self-Censorship: the media should check and verify information before publishing and avoid supporting or republishing outlets that spread disinformation.

- Public institutions staff should be trained on detection of disinformation and fake news.

- Increased demand for accountable governance on public officials.

Furthermore, mainstream media should check the scourge of fake news. As soon as information published is discovered not to be factual, the medium concerned should retract it and publicly apologise. Finally, with the launching of the campaign against fake news by the Federal Government, it is expected that the government will ensure compliance through creative means. 


\section{References}

Abdullahi, B. (2017 March 13). Democracy and the challenge of fake news. TheCable. Retrieved January 25,2019 from https://www.thecable.ng/democracy-challenge-fake-news

Africa Check (2018 November 12). Has Buhari’s government plunged Nigeria into $\$ 80$ billion in debt? Africa Check. Retrieved January 25, 2019 from https://africacheck.org/reports/has-buharis-government-plunged-nigeria-into80-billion-in-debt/

Agbese, D. (2017 December 31). The dangers of fake news. Daily Trust. Retrieved January 25,2019 from https://www.dailytrust.com.ng/the-dangers-of-fake-news.html

Aminu, D. (2018 September 30). Media, fake news and 2019 elections. TheGuardian. Retrieved January 25, 2019 from https:/guardian-ng.edn.ampproject.org/v/s/guardian.ng/politics/media-fake-news-and-2019-elections/

Ansip, A. (2017). Hate speech, populism and fake news on social media - towards an EU response. Retrieved January 27, 2019 from

https://ec.europa.eu/commission/commissioners/2014-2019/ansip/announcements/stament-vice-president-ansip-eur opean-parliament-strasbourg-plenary-debate-hate-speech-populism_en

Audu, U. (2018 September 9). Don speaks on factors that fuel fake news, hate speech. Premium Times Nigeria. Retrieved April 29, 2019 from

https://www.premiumtimesng.com\%2Ftop-news\%2F282992-don-speaks-on-factors-that-fuel-fake-news-hate-spee ch.html

BBC News (2018 November 12). World - Africa: What we've learnt about fake news in Africa. BBC News. Retrieved January 25, 2019 from https://www.bbc.com/news/world-africa-46138284

BBC News (2019 June 29). Fake news and Nigeria's herder crisis. BBC News. Retrieved April 12 , 2019 from https://www.bbc.com/world/africa/fake-news-and-nigerias-herder-crisi

Brille, S., \& Crovitz, G. (2019 January 16). NewsGuard now available on Microsoft Edge mobile apps for iOS and Android. NewsGuard. Retrieved January 26, 2019 from

https://www.newsguardtech.com/press/newsguard-now-available-on-microsoft-edge-mobile-apps-for-ios-and-andr oid/

Burt, T. (2018 April 13). On the Issues: Announcing the defending democracy programme. Microsoft. Retrieved January 26, 2019 from https://blogs.microsoft.com/on-the-issues/2018/04/13/announcing-the-defending-democracy-program/

CDD (2018). How fake news threatens our democracy. Centre for Democracy and Development (CDD), Abuja, Nigeria. Retrieved January 25, 2019 from http://cddwestafrica.org/wp-content/uploads/2018/07/Democracy-and-Disinformation.pdf

Collins Dictionary (2017). Word of the year 2017. Retrieved January 25, 2019 from https://www.collinsdictionary.com/woty

Davies, M. (2017). Fake news. Retrieved January 25, 2019 from https://corpus.byu.edu/now/help/fake-news.asp

Dubawa (2019). Fake news: If it's too bad to be true, maybe it is. Retrieved April 16, 2019 from https://dubawa.org/fake-news-if-its-too-bad-to-be-true-maybe-it-is/

Egan, J. (2018 December 11). We need writers now more than ever. Our democracy depends on it. TIME magazine. Retrieved April 16, 2019 from http://time.com/5475490/writers-truth-democracy-jennifer-egan/

EJN (2017). Ethics in the news: EJN report on challenges for journalism in the post-truth era. London: Ethical Journalism Network.

English Oxford Living Dictionaries (2019). Post-truth. Oxford University Press. Retrieved April 28, 2019 from https://en.oxforddictionaries.com/definitions/post-truth

Epstein, R. A. (2011). Direct democracy: Government of the people, by the people and for the people. Harvard Journal of Law and Public Policy, 34, 819-826.

Ezema, I. J., Ezeah, C. S., Ishiwu, B. N., \& Ukwueze, P. N. (2012). Freedom of information and Nigerian democracy: Issues and challenges. Proceeding of the 13th Annual Conference/Annual General Meeting, Nigerian Library Association, Enugu State Chapter, Enugu, 21-23 November 2012.

Hankey, S., Marrison, J. K., \& Naik, R. (2018). Data and democracy in the digital age. The Constitution Society. 
Harsin, J. (2018). Post-truth and critical communication studies. In J. Nussbaum (Ed.), Oxford research encyclopedias: Communication (pp.1-33). London: Oxford University Press. https://doi.org/10.1093/acrefore/9780190228613.013.757

Ibrahim, A. M., \& Adamu, M. A. (2016). ICT is not gender blind: A literary analysis of ICT gender inequality and its socio-economic impact in the developing world. In J. Wilson \& N. D. Gapsiso, (Eds.), Overcoming gender inequalities through technology integration (pp. 174-193). Hershey, PA: IGI Global. https://doi.org/10.4018/978-1-4666-9773-7.ch009

Ibrahim, A. M. (2017). The broadcast media and political campaign in Yobe State: A case study of Yobe Broadcasting Corporation (YBC), Damaturu. Beau Bassin, Mauritius: Lambert Academic Publishing, pp. 4-5.

IDC (2018 November). International declaration on information and democracy. Reporters without Borders. Retrieved January 26, 2019 from https://rsf.org/international_declaration_on_information_and_democracy.pdf

Itedge News (2018 September 10). Nigeria goes after fake news, hate speech as NBC reviews broadcasting code. Itedge News. Retrieved April 28, 2019 from

https://itedgenews.ng/2018/09/10/nigeria-goes-fake-news-hate-speech-nbc-reviews-broadcasting-code/

Jimoh, A. (2018 August 7). 2019: Fake news can lead to civil war - Lai Mohammed. Daily Trust. Retrieved January 25, 2019 from https://www.dailytrust.com.ng/2019-fake-news-can-lead-to-civil-war--lai-mohammed-264677.html

Kazeem, Y. (2018 November 29). Nigerian media houses are forming a coalition to combat fake news ahead of next year's elections. Quartz Africa. Retrieved January 25, 2019 from https://qz.com.cdn.ampproject.org/v/s//qz.com/africa/1478737/fake-news-media-collaborate-ahead-of-nigeria-2019 election/

Marama, N. (2017 August 10). Book Haram: UNIMAID denies resignation of 70 lecturers. Vanguard Nigeria. Retrieved April 28, 2019 from https://www.vanguardngr.com/2017/08/boko-haram-unimaid-denies-resignation-70-lecturers/

Mazzetti, M., Sullivan, E., \& Haberman, M. (2019 January 25). Indicting Roger Stone, Mueller shows link between Trump and WikiLeaks. The New York Times. Retrieved January 26, 2019 from https://www.nytimes.com/2019/01/25/us/politics/roger-stone-trump-mueller.html

McGonagle, T. (2017). 'Fake news': False fears or real concerns? Netherlands Quarterly of Human Rights, 35(4), 203-209. https://doi.org/10.1177/0924051917738685

Mendel, T. (2015). The UN special rapporteur on freedom of opinion and expression: Progressive development of international standards relating to freedom of expression. In T. McGonagle \& Y. Donders, (Eds.), The United Nations and freedom of expression and information: Critical perspectives (pp. 251-257). London: Cambridge University Press.

Nwachukwu, J. O. (2017 May 22). Ex-British lawmaker, Eric Stuart pronounces President Buhari dead. Daily Post. Retrieved January 25, 2019 from http://dailypost.ng/2017/05/22/exBritish_lawmaker_eric_stuart_pronounces_president_buhari_dead

Ogola, G. (2017 February 27). Africa has a long history of fake news after years of living with non-truth. The Conversation. Retrieved January 25, 2019 from

https://theconversation-com.cdn.ampproject.org/v/s/theconversation.com/amp/africa-has-a-long-history-of-fake-ne ws-after-years-of-living-in-non-truth-73332

Okakwu, E. (2018 July 11). Nigerian govt launches campaign against fake news. Premium Times. Retrieved January 25, 2019 from

https://www.premiumtimesng.com/news/more-news/275846-nigerian-govt-launches-campaign-against-fake-new.ht $\mathrm{ml}$

Okoli, A. (2017 November 6). Fake news is an affront to Nigeria's democracy. More Branches. Retrieved January 25, 2019 from https://www.morebranches.com,cdn,ampproject.org/v/s/www.morebranches.com/fake-news/

Okoro, E. M., Abara, B. A., Umagba, A. O., Ajonye, A. A., \& Isa, M. S. (2018). A hybrid approach to fake news detection on social media. Nigerian Journal of Technology, 37(2), 454-462. https://doi.org/10.4314/njt.v37i2.22

Oro, O. I. (2011). The Nigerian press: The journey so far. Continental Journal of Sustainable Development, 2(1), 8-19.

Pate, U. A. (2018 September 7). Fake news, Hate Speech and Nigeria's Democratic Sustenance. PowerPoint slides of a presentation at a colloquium to mark the Press Week of the Nigerian Union of Journalists, Plateau State Chapter, Jos, pp. 6-10. 
Pate, U. A., \& Idris, H. (2017). How journalists survived to report: Professionalism and risk management in the reporting of terror groups and violent extremism in North East Nigeria. In U. Carlsson \& R. Pöyhtäri, (Eds.), The Assault on Journalism: Building knowledge to protect freedom of expression (pp. 159-170). Gothenburg, Sweden: NORDICOM University of Gothenburg, p. 161.

Persily, N. (2017). The 2016 US election: Can democracy survive the internet? Journal of Democracy, 28(2), 63-76. https://doi.org/10.1353/jod.2017.0025

Siapera, E. (2018). Understanding new media. London: Sage, p.57.

Simon, J. (2017 February 25). Trump is damaging press freedom in the US and abroad. The New York Times. Retrieved January 26, 2019 from https://www.nytimes.com/2017/02/25/opinion/trump-is-damaging-press-freedom-in-the-us-and-abroad.html

Standage, T. (2017). The true history of fake news. 1843 Magazine. Retrieved January 25, 2019 from https://bit.ly/2sh9OYQ

Steinmetz, K. (2018 September 6). How your brain tricks you into believing fake news. TIME magazine. Retrieved April 16, 2019 from https://time.com/5362183/the-real-fake-news-crisis/

Ting, C. S. W., \& Song, S. G. Z. (2017). What lies beneath the truth: A literature review on fake news, false information and more. Singapore: Institute of Policy Studies.

Tower-Clark, C. (2018 October 4). Can I put an end to fake news? Don’t be so sure. Forbes. Retrieved January 26, 2019 from

https://www.forbes.com/sites/charlestowersclark/2018/10/04/can-ai-put-an-end-to-fake-news-dont-be-so-sure/\#4df 2edff $2 \mathrm{f} 84$

Wardle, C. (2017). Cited by Siapera, E. (2018). Understanding new media. London: Sage.

Wasserman, H., \& Madrid-Morales, D. (2018 November 21). Study sheds light on scourge of 'fake news' in Africa. The Conversation. Retrieved January 25, 2019 from

https://theconversation.com/study-shed-light-on-scourge-of-fake-news-in-africa-106946

Wight, C. (2017 November 17). A Robert De Niro theory of post-truth: ‘Are you talking to me?' The Conversation. Retrieved April 28, 2019 from

https://theconversation.com/a-robert-de-niro-theory-of-post-truth-are-you-talking-to-me-87606

\section{Copyrights}

Copyright for this article is retained by the author(s), with first publication rights granted to the journal.

This is an open-access article distributed under the terms and conditions of the Creative Commons Attribution license which permits unrestricted use, distribution, and reproduction in any medium, provided the original work is properly cited. 